\title{
From Disability to Death: A 20-Year Follow-Up from the Taiwan Longitudinal Study on Aging
}

\author{
Ching-Ju Chiu (ID) \\ Min-Chia Yang ${ }^{2}$ \\ Chi-Chang Huang ${ }^{3}$ \\ Chia-Ming Chang ${ }^{1,3}$ \\ 'Institute of Gerontology, College of \\ Medicine, National Cheng Kung \\ University, Tainan, 70I0I, Taiwan; \\ ${ }^{2}$ Department of Medicine, College of \\ Medicine, National Cheng Kung \\ University, Tainan, 70I0I, Taiwan; \\ ${ }^{3}$ Division of Geriatrics and Gerontology, \\ Department of Internal Medicine, \\ National Cheng Kung University Hospital, \\ Tainan, Taiwan
}

Background: In this study, factors associated with the duration of a disability before death in older adults who are moderately to severely disabled in Taiwan are investigated.

Methods: A nationally representative sample of older adults $(65+)$ in 1996 who died before $2016(n=1139)$ were analyzed to calculate their disability status and the length of time they were disabled before death.

Results: The mean period during which the participants experienced moderate to severe disability before death for older adults in Taiwan was 5.53 years $(\mathrm{SD}=3.15)$. Men who were overweight had an average of 1.17 more survival years $\left(\beta_{\text {overweight }}=1.17, p<0.05\right)$ as compared to those who were normal weight, and in the case of those who were cognitively impaired (SPMSQ $\leq 7$ ), years of survival were decreased by an average of 1.70 years as compared to those who were cognitively intact before death $(\beta \operatorname{cognition}=-1.70, p<0.01)$. The aforementioned effects were independent of age. In women, the number of diseases was the most dominant independent correlate for survival years $\left(\beta_{\text {disease }}=-0.34, p<0.05\right)$.

Conclusion: Disability distribution at various time points before death among the elderly in Taiwan was revealed in the study. At 10 years before death, $93 \%$ of the elderly were free from any ADL disabilities, and only 4\% reported more than three ADL disabilities. At 6 years before death, an average of $10 \%$ of the participants had more than three ADL disabilities, and at one year before death, moderate to severe disability increased to $38 \%$. Factors associated with the survival years among those who were moderately to severely disabled showed distinct gender differences.

Keywords: disability, duration before death, elderly, risk factor

\section{Introduction}

Disability among the elderly is a global issue, currently estimated to have affected 460 million people worldwide in 2011. ${ }^{1}$ Taiwan is one of the affected aging countries. In line with the government definitions, 1 or 2 disability items are defined as mildly disabled; 3 or 4 disability items are defined as moderately disabled, and 5 or 6 disability items are defined as severely disabled. ${ }^{2}$ According to a national survey in Taiwan, 0.48 million (16.5\%) of the elderly aged 65 and over experienced functional disability in 2015, and the number has been estimated to increase to 0.95 million by 2031., ${ }^{3,4}$ However, disability is not a consequence of aging. Individuals stay functionally intact or develop disability with wide range of heterogeneity. Some people die right after experiencing a disability, while others suffer from a disability for several years.

In the concept of active aging, health is an essential key point. Those who can live without assistance from others retain their dignity and thus have better quality
Correspondence: Min-Chia Yang Department of Medicine, College of Medicine, National Cheng Kung University, No. I, University Road, Tainan 70I0I, Taiwan

Tel +886-6-2353535 ext. 5739

$\mathrm{Fax}+886-6-3028175$

Email kh9531023@gmail.com 
of life. Being disabled and bedridden affects old people psychologically, ${ }^{5}$ making them and their families exhausted because caring for them requires money as well as mental and physical effort. Taking care of the disabled elderly is a complicated and strenuous job. ${ }^{6}$ First, caregivers are faced with choosing between their family and their career. Later, they experience economic burdens of as much as 1-2 thousand US dollars per month, as well as mental and physical burdens. ${ }^{7}$ One-fourth of caregivers experience high levels of stress, ${ }^{8}$ and $40.49 \%$ experience economic burdens. ${ }^{9}$ As the duration of a disability increases, the duration of caregiving also increases and so does the money being spent. Both the disabled elderly and their caregivers are confronted with higher morbidity and mortality rates. ${ }^{10}$ Thus, how long a disability lasts is crucial to the disabled elderly and their families. Consequently, as the life span of human beings increases, it is hoped that the duration of disabilities can be controlled as much as possible.

There are different disability patterns before death. Gill et al categorized these patterns into five categories, ${ }^{11}$ where some individuals have no disabilities and some remain persistently disabled. There are several variables associated with end-of-life disabilities, including age, sex, chronic disease, and BMI, among others. ${ }^{12-15}$ However, studies on this topic have typically focused on a specific variable, instead of a combination. ${ }^{16}$ How sociodemographic, physical, and psychological variables interact in the disability process is thus not fully understood. In addition, the degree of impact each of the variables has on the duration of disability remains unclear. The differences in each individual disability pattern may have been masked by the general nature of the research dedicated to this field. Studies examining the longitudinal impacts of either sociodemographic or physical variables are limited by the study period, usually $1-4$ years, ${ }^{11-13,17}$ where researchers attempted to draw disability trajectories. However, the limited periods under observation made it impossible to gain an overall perspective of disability and to estimate the burden on the family. In addition, study results may vary by country. Therefore, in this work, a nationally representative sample of older adults $(65+)$ in 1996 who died before 2016 were adopted to determine the disability development before death and the possible modifiable correlates in the sociodemographic, physical, and psychological domains. The identification of modifiable factors may serve to alleviate the adverse impacts of the period of disability.

\section{Methods}

\section{Participants}

In this study, the Taiwan Longitudinal Study on Aging (TLSA) was used to obtain the data. The TLSA is a selfreport nationally representative survey. It collects a wide range of sociodemographic, physical, psychological, and social data for middle-aged and elderly people in Taiwan from the Health Promotion Administration, Ministry of Health and Welfare. The 3rd-7th waves (1996 2011) of the TLSA data were used in this research. There were 5131 participants aged 50 and above interviewed in 1996. The 1999, 2003, 2007, and 2011 surveys followed the same group of people and recorded their disability data. We selected data for those aged above 65 in 1996 who died before $2016(n=1139)$.

To ascertain the date of death, we connected the TLSA data with the 1996-2016 death registration data provided by the Health Promotion Administration, Ministry of Health and Welfare, including an ID number and date of death. After connecting the cause of death data with the TLSA data, we were able to calculate the years of disability before death and the level of disability at that time. As shown in Figure 1, participant number $(\mathrm{N})$ in each year before death was contributed by all the participants with disability records before death. For example, the interview wave was in 1996, 1999, 2003, 2007, and 2011. Therefore, those who died in 1997, 2000, 2004, 2008, and 2012, contributed to data for disability status one year before death. Similarly, for those who died in 2016, their disability score on 1996-2011 TLSA data contributed to disability records before the death of $5,9,13,17$, and 20 years ago. The subgroup analyses further analyzed those who developed moderately to severe disabilities during the 1999, 2003, 2007, or 2011 follow-ups $(n=618)$ to determine the correlates associated with years before death among them.

\section{Measures}

Disability was assessed using the Activities of Daily Living (ADL) scale. ${ }^{18}$ It includes six items: bathing, dressing, eating, getting out of the bed, walking around a room, and using the toilet. Participants reporting having some difficulty, having a lot of difficulty, or being unable to do the movement in each item were coded 1 , whereas participants reporting having no difficulty doing the movement were coded 0 . The total for the ADL scale ranges from 0 to 6 , where 1 or 2 indicates that they are mildly 


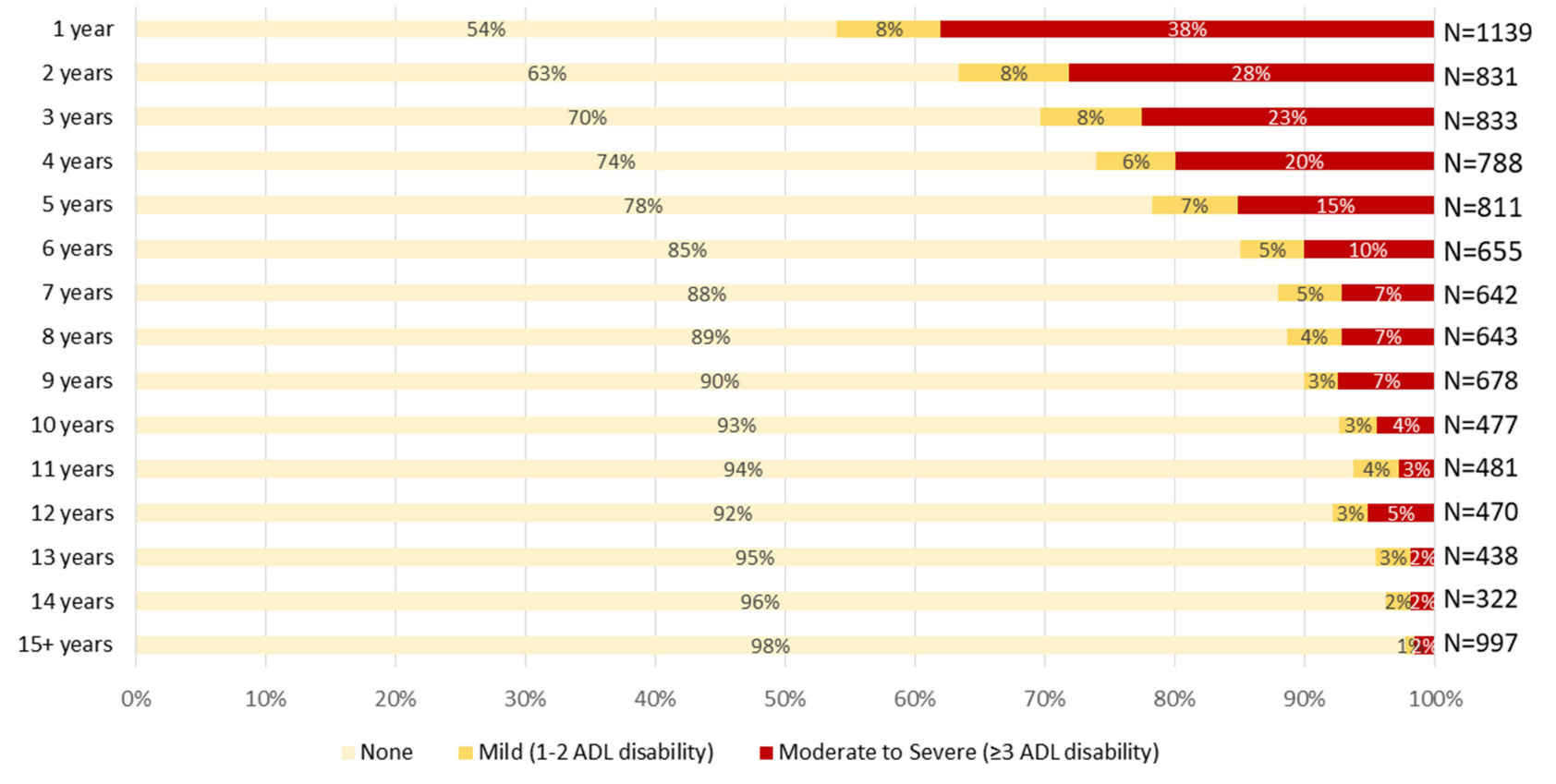

Figure I Disability distribution of the elderly at various time points before death.

Notes: Participant number $(\mathrm{N})$ in each year before death was contributed by all the participants with disability records before death. For example, the interview wave was in 1996, 1999, 2003, 2007, and 20II. Therefore, those who died in 1997, 2000, 2004, 2008, and 20I2, contributed to data for disability status one year before death. Similarly, for those who died in 2016, their disability score on 1996-201। TLSA data contributed to disability records before the death of 5, 9, I3, I7, and 20 years ago.

disabled; 3 or 4 indicates that they are moderately disabled, and 5 or 6 indicates that they are severely disabled.

The covariates examined in the study included sociodemographic, physical, psychosocial, and socioenvironmental variables. The sociodemographic variables included age, sex, education (illiterate, elementary school, junior high school, senior high school, and university and above), marital status (married/ partnered or not), if their children live with them, and the state of their financial situation (good: no stress related to this, vs bad: has a little or a lot of difficulty dealing with it).

Physical variables included chronic conditions, cognitive function, and BMI. Chronic conditions included hypertension, diabetes, heart disease, stroke, cancer, lung disease, arthritis, and hepatobiliary disease. These data were based on the question, "Did a doctor diagnose the disease?" The total score ranged from $0 \sim 8$. Cognitive function $^{19}$ was measured with the nine-item Short Portable Mental Status Questionnaire (SPMSQ). This questionnaire includes orientation (date, day of week, the current location, home address, and mother's maiden name), memory (past and present president), and a concentration and mental tracking assessment (20 minus 3 , and minus 3 , and minus 3 ), where the score was 1 if the answer was correct and 0 if the answer was wrong. The total score ranged from $0 \sim 9$, with a higher score representing better cognition and a score of 7 9 indicating intact $\operatorname{cognition}^{20,21}$ The body mass index ${ }^{22}$ $(\mathrm{BMI})=$ Weight $(\mathrm{kg}) /$ Height $(\mathrm{m})^{2}$ was measured according to the standards set forth by the World Health Organization, where a BMI $<18.50$ indicates underweight; $18.50 \leq \mathrm{BMI}<25.00$ indicates normal weight, and $\mathrm{BMI} \geq$ 25.00 indicates overweight.

The psychosocial variables included depressive symptoms, stress, and social participation. The 10-item Center for Epidemiologic Studies Depression Scale (CES-D 10) was used to measure depression. ${ }^{23,24}$ The 10-item CESD scale has been proven to be a reliable and valid measurement of geriatric depression in Taiwan, and includes 8 negative questions and 2 positive questions: poor appetite, feeling tired, cannot sleep well, lonely, feeling sad, people are unfriendly, depressed, lacking strength, happy, life is good. According to the answer (never, sometimes, usually, always), each negative question was scored $0,1,2,3$, respectively. The positive questions were opposite and were scored as 3,2, 1,0 , respectively. If the sum of these questions $\geq 10$, the participant was considered to be suffering from depression. ${ }^{25-27}$ Stress was assessed with five questions about stress in the TLSA and included economic status, job, health, family relationships, family's 
economic status, jobs, and health. The total score was the sum of how many kinds of stress they were experiencing, where a greater score indicated higher stress levels. Social participation included eight types of clubs (community social groups, religious groups, industry groups, political groups, public interest groups, hometown associations, elderly groups, and learning clubs). Participation in any of these groups was recognized as engaging in social participation.

The socio-environmental variables included living situation and living alone and included living in a nursing home and others, as well as living with family members or not.

\section{Statistical Analysis}

After connecting the cause of death data with the 1996, 1999, 2003, 2007, and 2011 TLSA data, the deceased elderly were selected. We examined the distribution of their disability state at various time points. Specifically, we identified the disabled status for participants in every interview wave in 1996, 1999, 2003, 2007, and 2011, and then linked this data to their death data to calculate the changes and the length of time they had had each disability before death. The disability distribution of the elderly at various time points before death is summarized in Figure 1.

Next, we selected the moderately to severely disabled data because their ratio increased remarkably as the individuals approached death. However, because the TLSA interviewed the participants every three to four years, the exact time at which they became disabled could not be exactly ascertained. Therefore, we estimated the development of the disability by the midpoint between the self-reported disabled interview wave and the year of the previous interview wave. An example would be a man who was not disabled in 2003 but became moderately disabled in 2007 and died in 2012. He would be labeled as moderately disabled for $7=2012-(2007+2003) / 2$ years before death. We compared the differences in the years of disability before death for possible risk factors by using chi-square tests for the categorical variables and t-tests for the continuous variables.

Variables that turned out to be significant or were of interest were selected in order to learn more about how much these variables affected the years of disability before death. Using the SAS PROC GLM procedure, we used six models to do the regression analysis of the variables and years of disability before death. Model 1 evaluated the effects of the sociodemographic variables, age, and sex on the years of disability before death. In models $2-6$, the physical, psychological, social variables were added progressively. The same method was used to analyze gender.

\section{Results}

Figure 1 shows the disability distribution of the sample. As the individual approached death, the level of disability increased. The proportion of the respondents who were moderately to severely disabled increased rapidly and accounted for $4 \%, 15 \%$, and $38 \%$ of those who died 10 years, 5 years, and 1 year later, respectively.

The characteristics of the moderate to severely disabled elderly in the study sample $(n=618)$ are presented in Table 1 . The mean age was $80.91 \pm 6.94$, and the average moderate to severe years of disability was 5.5 years. Among these individuals, $46.44 \%$ were male. Adults who suffered longer from disability were significantly more likely to be female, younger, with fewer diseases, not living in a nursing home, with normal cognitive function, and heavier. Those who lived with their children suffered from longer periods of disability; however, more children living with them did not mean a longer period of disability. Some diseases, including lung disease, and cancer, shortened the duration of disability while other diseases did not affect it. In addition, the years of disability before death did not differ by education, the presence or absence of partners, the number of children, economic pressure, amount of stress, depression, or the degree of social participation.

The results of the linear regression examining the effect of the various variables on the years of disability is presented in Table 2. Model 1 ( $\mathrm{R}$ square $=0.07$ ) showed the effects of the sociodemographic variables, where age had a negative effect $\left(\beta_{\text {age }}=-0.10, p<0.001\right)$, and being female had positive effect $\left(\beta_{\text {sex }}=0.99, p<0.001\right)$. Age and sex explained $7 \%$ of the results. In Model 2 , the number of diseases $\left(\beta_{\text {disease }}=-0.25, p<0.01\right)$ had negative effects on years of disability before death and further explained $1 \%$ of the result. In Model 3, BMI further contributed another 3\% of the variances in the duration of disability before death, and being overweight $\left(\beta_{\text {overweight }}=0.87, p<0.05\right)$ also had significant effects on predicting the years of disability before death. In Model 4, the results indicated that cognitive function $\left(\beta_{\text {cognition }}=-1.49, p<0.001\right)$ had significant negative effects on years of disability before death. In models 5 and 6, the psychological and social-environmental variables showed a weak association with years of disability before 
Table I Descriptive Statistics for the Elderly with Moderate to Severe Levels of Disability

\begin{tabular}{|c|c|c|c|}
\hline Variable & $\mathbf{N}(\%)$ & Years Before Death (Mean \pm SD) & $\mathbf{F} / \mathbf{t}$ \\
\hline $\mathbf{N}$ & 618 & $5.53 \pm 3.15$ & \\
\hline AGE & $80.91 \pm 6.94(65.00-104.00)$ & & $29.33 * * *$ \\
\hline $65-74$ & $112(18.12)$ & $6.15 \pm 3.91$ & $5.23 *$ \\
\hline $75-$ & $506(81.88)$ & $5.40 \pm 2.94$ & \\
\hline Gender & & & $14.36 * * *$ \\
\hline Men & $287(46.44)$ & $5.02 \pm 2.86$ & \\
\hline Women & $331(53.56)$ & $5.98 \pm 3.32$ & \\
\hline Education & & & 1.25 \\
\hline Illiterate & $245(39.64)$ & $5.65 \pm 3.07$ & \\
\hline Elementary school & $253(40.94)$ & $5.56 \pm 3.30$ & \\
\hline Junior high school & $62(10.03)$ & $4.7 I \pm 2.28$ & \\
\hline Senior high school & $34(5.50)$ & $5.77 \pm 3.90$ & \\
\hline College and above & $24(3.88)$ & $5.8 I \pm 2.90$ & \\
\hline Marital status & & & 0.38 \\
\hline Married/partnered & $254(41.17)$ & $5.63 \pm 3.20$ & \\
\hline Other & $363(58.83)$ & $5.47 \pm 3.11$ & \\
\hline Living children & $4.40 \pm 2.05$ & & 1.68 \\
\hline 0 & $21(3.40)$ & $4.95 \pm 3.16$ & 0.74 \\
\hline$\geq 1$ & $597(96.60)$ & $5.55 \pm 3.15$ & \\
\hline Living with children & $1.36 \pm 7.86$ & & 1.18 \\
\hline 0 & $269(43.88)$ & $5.25 \pm 2.94$ & $4.44 *$ \\
\hline$\geq 1$ & $344(56.12)$ & $5.78 \pm 3.30$ & \\
\hline Economic stress & & & 0.44 \\
\hline Stressed & $172(58.90)$ & $6.5 I \pm 3.43$ & \\
\hline Non-stressed & $120(41.10)$ & $6.23 \pm 3.55$ & \\
\hline Life stress & $1.73 \pm 1.42$ & & 0.17 \\
\hline <average & I $48(50.5 \mathrm{I})$ & $6.25 \pm 3.16$ & 0.42 \\
\hline$\geq$ average & 145 (49.49) & $6.52 \pm 3.78$ & \\
\hline Depression & $12.62 \pm 8.08$ & & 0.83 \\
\hline$<10$ & $117(39.80)$ & $6.68 \pm 3.52$ & 1.32 \\
\hline$\geq 10$ & $177(60.20)$ & $6.20 \pm 3.44$ & \\
\hline Social participation & $0.23 \pm 0.54$ & & 2.88 \\
\hline Living situation & & & $|6.8| * * *$ \\
\hline Normal & $490(79.29)$ & $5.80 \pm 3.28$ & \\
\hline Nursing home & I $28(20.7 \mid)$ & $4.53 \pm 2.35$ & \\
\hline Live alone & & & 0.1 \\
\hline No & $572(92.56)$ & $5.52 \pm 3.16$ & \\
\hline Yes & $46(7.44)$ & $5.67 \pm 3.06$ & \\
\hline Number of diseases & $2.47 \pm 1.32$ & & $6.16 *$ \\
\hline Classification I & & & 0.11 \\
\hline 0 & $76(12.30)$ & $5.87 \pm 3.33$ & \\
\hline $\mathrm{I}-2$ & $310(50.16)$ & $5.70 \pm 3.32$ & \\
\hline$\geq 3$ & $232(37.54)$ & $5.20 \pm 2.8 I$ & \\
\hline
\end{tabular}


Table I (Continued).

\begin{tabular}{|c|c|c|c|}
\hline Variable & $\mathbf{N}(\%)$ & Years Before Death (Mean \pm SD) & $\mathbf{F} / \mathbf{t}$ \\
\hline \multicolumn{4}{|l|}{ Classification II } \\
\hline High blood pressure & $352(56.96)$ & $5.63 \pm 3.43$ & 0.43 \\
\hline Diabetes & $174(28.16)$ & $5.49 \pm 2.94$ & 0.04 \\
\hline Heart disease & $205(33.17)$ & $5.54 \pm 2.94$ & 0.00 \\
\hline Stroke & $205(33.17)$ & $5.25 \pm 2.97$ & 2.44 \\
\hline Cancer & $53(8.58)$ & $4.33 \pm 2.54$ & $8.59 * *$ \\
\hline Lung disease & $137(22.17)$ & $4.82 \pm 2.82$ & $9.15 * *$ \\
\hline Arthritis & $15 \mid(24.43)$ & $5.75 \pm 3.42$ & 0.99 \\
\hline Hepatobiliary disease & $55(8.90)$ & $5.26 \pm 3.28$ & 0.45 \\
\hline Cognition[SPMSQ] & $2.87 \pm 3.21$ & & $49.15^{* * *}$ \\
\hline $8-9$ & $70(12.43)$ & $7.11 \pm 3.85$ & $19.95 * * *$ \\
\hline $0-7$ & $493(87.57)$ & $5.38 \pm 2.92$ & \\
\hline BMI & $21.90 \pm 3.89$ & & $12.84 * * *$ \\
\hline WHO & & & $6.68 * * *$ \\
\hline $\mathrm{BMI}<18.50$ & $82(17.60)$ & $4.93 \pm 3.25$ & \\
\hline$|8.50 \leq \mathrm{BM}|<25.00$ & $293(47.4 I)$ & $5.63 \pm 3.18$ & \\
\hline $25 \leq \mathrm{BMI}$ & 91 (14.72) & $6.73 \pm 3.66$ & \\
\hline
\end{tabular}

Notes: ${ }^{*} p<0.05,{ }^{*} p<0.01,{ }^{* * *} p<0.001$, bold values are statistically significant.

Table 2 Regression Coefficients of Factors Predicting Years Before Death for Older Adults Who Were Moderately to Severely Disabled

\begin{tabular}{|c|c|c|c|c|c|c|}
\hline & Model I & Model 2 & Model 3 & Model 4 & Model 5 & Model 6 \\
\hline Intercept & $6.55 * * *$ & $7.20 * * *$ & $7.75 * * *$ & $8.37 * * *$ & $9.68 * * *$ & $9.61 * * *$ \\
\hline \multicolumn{7}{|l|}{ Sociodemographic } \\
\hline Age & $-0.10 * * *$ & $-0.10 * * *$ & $-0.12 * * *$ & $-0.09 * * *$ & $-0.12 * * *$ & $-0.12 * * *$ \\
\hline Gender $[\text { women }]^{a}$ & $0.99 * * *$ & $0.98^{* * * *}$ & $0.82 * *$ & $0.90 * *$ & 0.87 & 0.94 \\
\hline \multicolumn{7}{|l|}{ Physical } \\
\hline Number of diseases & & $-0.25 * *$ & $-0.28 * *$ & $-0.23 *$ & $-0.45 *$ & $-0.45 *$ \\
\hline BMI [underweight] & & & -0.62 & -0.52 & -0.68 & -0.72 \\
\hline BMI [overweight] & & & $0.87 *$ & $0.82 *$ & 0.69 & 0.73 \\
\hline Cognitive impaired (SPMSQ $\leqq 7)^{c}$ & & & & $-1.49 * * *$ & -0.69 & -0.64 \\
\hline \multicolumn{7}{|l|}{ Psychological } \\
\hline Depressive symptoms $[C E S D \geq 10]^{d}$ & & & & & -0.61 & -0.55 \\
\hline \multicolumn{7}{|l|}{ Social-environmental } \\
\hline Living with children ${ }^{\mathrm{e}}$ & & & & & & -0.23 \\
\hline Social participation & & & & & & 0.30 \\
\hline Adjusted R square & 0.07 & 0.08 & 0.11 & 0.11 & 0.11 & 0.11 \\
\hline
\end{tabular}

Notes: ${ }^{*} p<0.05,{ }^{* *} p<0.01$, ${ }^{* * *} p<0.00$ I, bold values are statistically significant. ${ }^{\mathrm{a}}$ Men as a reference. ${ }^{\mathrm{b}}$ Normal weight as a reference. ${ }^{\mathrm{c}} \mathrm{SPMSQ} \geq 8$ as a reference. ${ }^{\mathrm{d}} \mathrm{CESD}<10$ as a reference. ${ }^{e}$ Not living with children as a reference.

death. However, the addition of these variables made the protective effects of gender invisible and thus insignificant. This might have been a result of the association between sex and psychological and social-environmental variables, which in turn affected the outcome.
Table 3 presents the regression analysis by sex. Age was the most important factor for women, explaining $7 \%$ of the results as compared to men, where age only contributed $3 \%$. In Model 2, based on the R squared increment and also the estimated coefficient for the number of diseases in terms of 


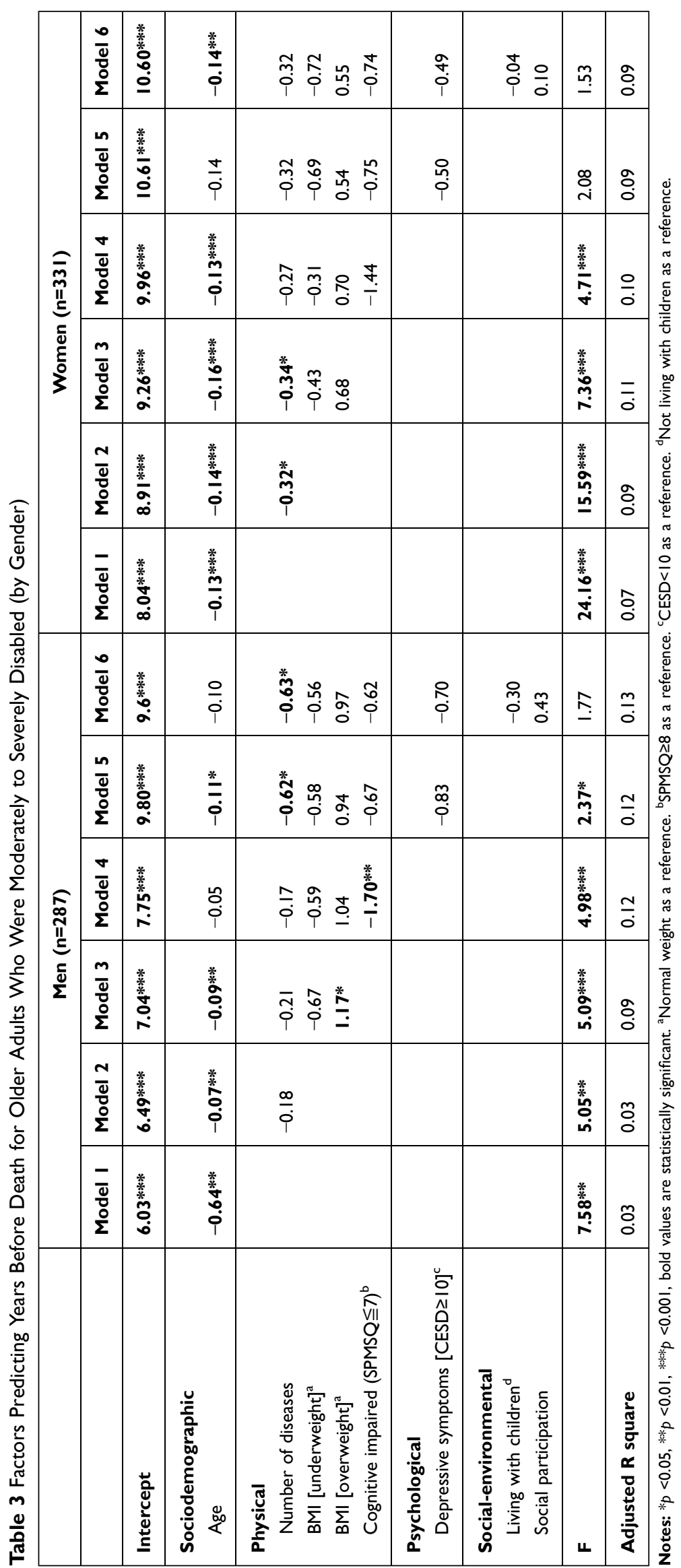


predicting years before death, the results suggested that the number of diseases was a key factor for women $(\beta=-0.34$, $p<0.05)$, but it was not a key factor for men. For men, BMI $(\beta=1.17, p<0.05)$ and cognitive function $(\beta=-0.70, p<$ $0.01)$ were significant predictors of years of disability before death, whereas in Model 3, these factors further explained an additional $6 \%$ and $2 \%$, respectively, of the results. However, $\operatorname{BMI}(\beta=-0.43, p>0.05)$ and cognitive function $(\beta=-1.44$, $p>0.05)$ only had a weak association to years before death women.

\section{Discussion}

A good or bad death is a critical issue for older adults with moderate to severe disabilities. Although whether a longer or shorter duration for older adults who are moderately to severely disabled is preferable is still controversial, quality of life in the last journey rather than quantity has become increasingly more valued. This study, by tracing a nationally representative sample of older adults who died during a twenty-year follow-up revealed the years of moderate and severe disability and the associated factors. It was found that for older adults in Taiwan, the proportion of moderate and severe disabilities increased rapidly as death approached. The mean of the years of disability before death for those who were moderately or severely disabled in Taiwan during the study period was 5.53 years. Importantly, factors predicting duration (years) before death were distinct by gender: Age and number of diseases were the most important factors for women, whereas BMI and cognitive function were the most significant predictors for men in terms of predicting years of disability before death.

Through an examination of deceased elderly in our study, we found that as they approached death, there was an increase in moderate to severe disability. This result matched the findings of previous studies. ${ }^{17}$ After analyzing these moderately to severely disabled elderly individuals, we found that in healthier people, the years of disability before death appeared to be longer. There were several variables significantly related to the years of disability before death. Among them, the most important variables were age and sex. With each year, the disability duration decreased by 0.1 of a year ( $\beta$ age $=-0.10, p<0.001$ ), where women had 0.99 of a year more disability than men ( $\beta$ sex $=0.99, p<0.001)$. The gender differences are discussed in the next paragraph. The second factors of importance were cognitive function and BMI. It is worth noting that compared to normal weight, being overweight and underweight appeared to have different effects on the years of disability before death, where there was an obesity paradox. Lastly, psychosocial variables, including depressive symptoms and less social participation, had a weak association with fewer survival years for those who were moderately to severely disabled after accounting for age and physical health. However, this may have been due to the floor effect.

According to the statistics from the Taiwan Ministry of Health and Welfare in 2017, the average healthy life expectancy of men was 69.0 years old, and their life expectancy was 77.3 years old. Men suffered for 8.3 years and, at the same time, women suffered for 9.8 years (83.7-73.9). ${ }^{28}$ Women thus had a longer period of poor quality of life than men. In the results of our study, it was clear that the average duration of moderate to severe disability before death was 5.02 years for men and 5.98 years for women, which indicated significant differences between men and women. Our results revealed that years of disability in men decreased by 0.18 of a year before death for every additional disease. However, women decreased almost twice as much as men, by 0.32 of a year per disease. In previous research, whether in foreign or domestic reports, women evaluated their health to be worse than men, and they were more sensitive to their comorbidities. That is, when they suffered from a disease, they were affected more psychologically. On the other hand, men often felt that they were in good health, had fewer medical visits and examinations, and went to the doctor later than women, which may have also made this variable, the number of diseases, less significant in men. $^{29-32}$

In our study, younger and healthier patients suffered longer from moderate or severe disabilities. However, this study found that being overweight increased disability before death by 0.87 of a year more than being normal weight. This situation was more obvious in men, where overweight men added 1.17 years and overweight females added 0.68 of a year. Being overweight led to a longer duration of disability before death than normal weight, which met the obesity paradox. Overweight will cause a higher risk of some diseases but lead to a lower rate of mortality. ${ }^{33-37}$ It appears that being overweight provides protection from becoming disabled, mainly due to the effect of better nutritional status in obese elderly. ${ }^{38,39}$ Thus, weight control in the elderly and whether the use of BMI is an effective way to judge nutritional status in the elderly should be further examined. 
Our study had several advantages. First, the TLSA is nationally representative longitudinal survey. Unlike existing studies focused on the trajectory before death, which often followed participants for $1-4$ years, ${ }^{11,12,17,40}$ the average length of time the elderly people under consideration were moderately and severely disabled was 5.53 years according to our study. Second, previous studies seldom mentioned the effects of psychological variables. This study addresses this shortcoming by analyzing psychological variables. Although it was found in the present study that the addition of psychological and socialenvironmental variables led to a weak association with duration of disability, this may have been due to the limited variances in the psychological and socialenvironmental factors measured in the present study. The roles that psychological and social-environmental variables play during end-of-life should be carefully addressed in this line of research.

There are some limitations in our study. First, the TLSA is a self-report survey. The previous studies on this topic found that the economic situation of the family is highly related to the presence of disability and the morbidity rate, which would affect the duration of disability prior to death. ${ }^{41-44}$ However, this variable was not significant in the present study. The validity of selfreported family income warrants further testing. Second, the TLSA investigates every 3 or 4 years, but we were not able to determine the exact year when this population became disabled. Instead, we estimated this based on the mean of the non-disabled wave and disabled wave. The study would have been better with a more concise time to death. Lastly, the TLSA data and the death data were not available on time. Although the aging and disability trend was continuing, we were not able to provide the latest analysis. There might therefore be some inaccuracies that cause the result to not fully reflect the current reality.

\section{Conclusions and Implications}

This study, by tracing a nationally representative sample of older adults who died during a twenty-year follow-up, revealed that the mean period during which this population experienced moderate to severe disability before death in Taiwan was 5.53 years $(\mathrm{SD}=3.15)$. The proportion of respondents who were moderately to severely disabled increased rapidly and accounted for $4 \%, 15 \%$, and $38 \%$ of those who died 10 years, 5 years, and 1 year later, respectively. Young age, being female, living with one's children, fewer chronic conditions, better cognitive function, and being overweight were associated with a longer duration of disability before death. However, gender differences did exist: Age and number of diseases were the most important factors for women, whereas BMI and cognitive function were the most significant predictors for men in terms of predicting years of disability before death. We believe that the findings from this national-wide longitudinal study will shed light on estimating end of life based on associated factors, potentially guiding genderspecific elderly end-of-life care.

\section{Abbreviations}

BMI, body mass index; TLSA, Taiwan Longitudinal Study on Aging; ADL, Activities of Daily Living; SPMSQ, Short Portable Mental Status Questionnaire; CES-D, Center for Epidemiologic Studies Depression Scale.

\section{Data Sharing Statement}

The data that support the findings of this study are available from Health Data Science Center, but restrictions apply to the availability of these data, which were used under license for the current study, and so are not publicly available. Data are however available from the authors upon reasonable request and with permission of the Health Data Science Center.

\section{Ethics Approval and Consent to Participate}

This study was approved by the Institutional Review Board (IRB) of National Cheng Kung University Hospital in Taiwan (No. B-ER-104-077) and informed consent was waived.

\section{Acknowledgments}

We are grateful to the Health Data Science Center, National Cheng Kung University Hospital for providing administrative and technical support.

\section{Author Contributions}

All authors made a significant contribution to the work reported, whether that is in the conception, study design, execution, acquisition of data, analysis and interpretation, or in all these areas; took part in drafting, revising or critically reviewing the article; gave final approval of the version to be published; have agreed on the journal to which the article has been submitted; and agree to be accountable for all aspects of the work. 


\section{Funding}

This work was supported by a grant from the Taiwan Ministry of Science and Technology (MOST 108-2813C-006-134-B) and Summer Research Project Grant no. NCKUMCS2018047 from the College of Medicine at National Cheng Kung University. The funders had no role in study design, data collection and analysis, decision to publish, or preparation of the manuscript.

\section{Disclosure}

The authors declare that they have no competing interests.

\section{References}

1. Hartley S, Ilagan V, Madden R, et al. World Report on Disability. WHO: WHO Library Cataloguing-in-Publication Data; 2011.

2. Ministry of Health and Welfare T. Taiwan Ten-Year Long-Term Care Program 2.0 (2017 2026). Ministry of Health and Welfare, Taiwan; 2016.

3. Council ND. Projected Population of the Republic of China (2014 2061). National Development Council; 2014.

4. Chu T-K, Peng M-C. Planning the important basic database of longterm insurance-National Long-Term Care Needs Survey. Public Governance Q. 2015.

5. Bruce ML, Seeman TE, Merrill SS, Blazer DG. The impact of depressive symptomatology on physical disability: macArthur studies of successful aging. Am J Public Health. 1994;84(11):1796-1799. doi:10.2105/AJPH.84.11.1796

6. Stone R, Cafferata GL, Sangl J. Caregivers of the Frail Elderly: a National Profile. Gerontologist. 1987;27(5):616-626. doi:10.1093/ geront/27.5.616

7. Hsu S-M, Chiou C-J. Stressors and coping behavior of family caregivers: the example of a support group. J Nurs. 2003;50 (5):47-55.

8. Health Promotion Administration MoHaW, Taiwan. Aging Society White Book. Taiwan: Health Promotion Administration, Ministry of Health and Welfare; 2015.

9. Department of Health EY, Taiwan. National Long-Term Care Needs Survey Statistic Report (2nd Stage). Taiwan: Department of Health, Executive Yuan; 2013.

10. Schulz R, Beach SR. Caregiving as a risk factor for mortality: the Caregiver Health Effects Study. JAMA. 1999;282(23):2215-2219. doi:10.1001/jama.282.23.2215

11. Gill TM, Gahbauer EA, Han L, Allore HG. Trajectories of disability in the last year of life. $N$ Engl J Med. 2010;362(13):1173-1180. doi:10.1056/NEJMoa0909087

12. Smith AK, Walter LC, Miao Y, Boscardin WJ, Covinsky KE. Disability during the last two years of life. JAMA Intern Med. 2013;173(16):1506-1513. doi:10.1001/jamainternmed.2013.8738

13. Nusselder WJ, Looman CW, Mackenbach JP. The level and time course of disability: trajectories of disability in adults and young elderly. Disabil Rehabil. 2006;28(16):1015-1026. doi:10.1080/ 09638280500493803

14. Ohmori K, Kuriyama S, Hozawa A, Ohkubo T, Tsubono Y, Tsuji I. Modifiable factors for the length of life with disability before death: mortality retrospective study in Japan. Gerontology. 2005;51 (3):186-191. doi:10.1159/000083992

15. Ferrucci L, Turchi A, Fumagalli S, et al. Sex-related differences in the length of disability prior to death in older persons. Aging Clin Exp Res. 2003;15(4):310-314. doi:10.1007/BF03324515
16. Lin C-H, Liu S-C. Healthy life expectancy for successful aging and active aging elderly in Taiwan. Taiwan J Public Health. 2013;32 (6):562-575.

17. Li LW. Trajectories of ADL disability among community-dwelling frail older persons. Res Aging. 2005;27(1):56-79. doi:10.1177/ 0164027504271348

18. Katz S, Ford AB, Moskowitz RW, Jackson BA, Jaffe MW. Studies of illness in the aged: the index of ADL: a standardized measure of biological and psychosocial function. JAMA. 1963;185(12):914-919. doi:10.1001/jama.1963.03060120024016

19. Pfeiffer E. A short portable mental status questionnaire for the assessment of organic brain deficit in elderly patients. $J$ Am Geriatr Soc. 1975;23(10):433-441. doi:10.1111/j.1532-5415.1975.tb00927.x

20. Purser JL, Fillenbaum GG, Pieper CF, Wallace RB. Mild cognitive impairment and 10-year trajectories of disability in the Iowa established populations for epidemiologic studies of the elderly cohort. J Am Geriatr Soc. 2005;53(11):1966-1972. doi:10.1111/j.1532-5415.2005.53566.x

21. Taylor DH Jr, Schenkman M, Zhou J, Sloan FA. The relative effect of Alzheimer's disease and related dementias, disability, and comorbidities on cost of care for elderly persons. J Gerontol B Psychol Sci Soc Sci. 2001;56(5):S285-S293. doi:10.1093/geronb/56.5.S285

22. Organization WH. Obesity: Preventing and Managing the Global Epidemic. World Health Organization; 2000.

23. Lee K-L, Ou Y-L, Chen S-H, Weng L-J. The psychometric properties of a short form of the CES-D used in the Taiwan Longitudinal Study on Aging. Formos J Mental Health. 2009;22(4):383-410.

24. Radloff LS. The CES-D scale: a self-report depression scale for research in the general population. Appl Psychol Meas. 1977;1 (3):385-401. doi:10.1177/014662167700100306

25. Fan W-T, Ku P-W. Relationships between different types of physical activity and depressive symptoms in older adults. NCUE Phys Educ. 2012;11:42-54.

26. Ku P-W, Fox KR, Chen L-J. Physical activity and depressive symptoms in Taiwanese older adults: a seven-year follow-up study. Prev Med. 2009;48(3):250-255. doi:10.1016/j.ypmed.2009.01.006

27. Zhang W, O'Brien N, Forrest JI, et al. Validating a shortened depression scale (10 item CES-D) among HIV-positive people in British Columbia, Canada. PLoS One. 2012;7(7)e40793.

28. Ministry of Health and Welfare T. Gender Statistics Image of Health and Welfare (July 2019). Ministry of Health and Welfare T, editor. Taiwan: Ministry of Health and Welfare;2019.

29. Chang L-Y, Yang M-L, Jhao J-Y. Latent healthcare utilization classification and objective health measures. Taiwan $J$ Sociol. 2011;46:207-247.

30. Bertakis KD, Azari R, Helms LJ, Callahan EJ, Robbins JA. Gender differences in the utilization of health care services. J Fam Pract. 2000;49(2):147.

31. Redondo-Sendino Á, Guallar-Castillón P, Banegas JR, RodríguezArtalejo F. Gender differences in the utilization of health-care services among the older adult population of Spain. BMC Public Health. 2006;6(1):155. doi:10.1186/1471-2458-6-155

32. Green CA, Pope CR. Gender, psychosocial factors and the use of medical services: a longitudinal analysis. Soc Sci Med. 1999;48 (10):1363-1372. doi:10.1016/S0277-9536(98)00440-7

33. Lavie CJ, Milani RV, Ventura HO. Obesity and cardiovascular disease: risk factor, paradox, and impact of weight loss. $\mathrm{J} \mathrm{Am} \mathrm{Coll}$ Cardiol. 2009;53(21):1925-1932. doi:10.1016/j.jacc.2008.12.068

34. Lavie CJ, McAuley PA, Church TS, Milani RV, Blair SN. Obesity and cardiovascular diseases: implications regarding fitness, fatness, and severity in the obesity paradox. J Am Coll Cardiol. 2014;63 (14):1345-1354. doi:10.1016/j.jacc.2014.01.022

35. Fonarow GC, Srikanthan P, Costanzo MR, et al. An obesity paradox in acute heart failure: analysis of body mass index and inhospital mortality for 108927 patients in the Acute Decompensated Heart Failure National Registry. Am Heart J. 2007;153(1):74-81. doi:10.1016/j.ahj.2006.09.007 
36. Uretsky S, Messerli FH, Bangalore S, et al. Obesity paradox in patients with hypertension and coronary artery disease. Am J Med. 2007;120(10):863-870. doi:10.1016/j.amjmed.2007.05.011

37. Curtis JP, Selter JG, Wang Y, et al. The obesity paradox: body mass index and outcomes in patients with heart failure. Arch Intern Med. 2005;165(1):55-61. doi:10.1001/archinte.165.1.55

38. Deschamps V, Astier X, Ferry M, Rainfray M, Emeriau J, BarbergerGateau P. Nutritional status of healthy elderly persons living in Dordogne, France, and relation with mortality and cognitive or functional decline. Eur J Clin Nutr. 2002;56(4):305-312. doi:10.1038/sj. ejcn. 1601311

39. Oreopoulos A, Kalantar-Zadeh K, Sharma AM, Fonarow GC. The obesity paradox in the elderly: potential mechanisms and clinical implications. Clin Geriatr Med. 2009;25(4):643-659. doi:10.1016/j. cger.2009.07.005

40. Liu Z, Han L, Wang X, Feng Q, Gill TM. Disability prior to death among the oldest-old in China. J Gerontol a Biol Sci Med Sci. 2019;74(3):433. doi:10.1093/gerona/gly266
41. Potente C, Monden C. Disability pathways preceding death in England by socio-economic status. Popul Stud. 2018;72 (2):175-190. doi:10.1080/00324728.2018.1458993

42. Banks J, Muriel A, Smith JP. Disease prevalence, disease incidence, and mortality in the United States and in England. Demography. 2010;47(1):S211-S231. doi:10.1353/dem.2010.0008

43. Jiang Y, Zheng H, Zhao T. Socioeconomic status and morbidity rate inequality in China: based on nhss and charls data. Int J Environ Res Public Health. 2019;16(2):215. doi:10.3390/ijerph16020215

44. Demakakos P, Biddulph JP, Bobak M, Marmot MG. Wealth and mortality at older ages: a prospective cohort study. J Epidemiol Community Health. 2016;70(4):346-353. doi:10.1136/jech-2015206173
Clinical Interventions in Aging

\section{Publish your work in this journal}

Clinical Interventions in Aging is an international, peer-reviewed journal focusing on evidence-based reports on the value or lack thereof of treatments intended to prevent or delay the onset of maladaptive correlates of aging in human beings. This journal is indexed on PubMed Central, MedLine, CAS, Scopus and the Elsevier
Dovepress

Bibliographic databases. The manuscript management system is completely online and includes a very quick and fair peer-review system, which is all easy to use. Visit http://www.dovepress.com/ testimonials.php to read real quotes from published authors. 